\title{
Comparing post-event and pre-event damage assessment: Information gaps and lessons learnt
}

\author{
Guido Minucci ${ }^{1, a}$, Mariano Garcia-Fernandez ${ }^{3}$, Scira Menoni ${ }^{1}$, Daniela Molinari ${ }^{2}$, Maria-Jose Jimenez ${ }^{3}$, Marina Tamara \\ Mendoza ${ }^{1}$, Francesco Ballio ${ }^{2}$, Nicola Berni ${ }^{4}$, Cristina Cedazo Tabernero ${ }^{3}$, Rosa Mata Francès ${ }^{5}$ \\ ${ }^{1}$ Department of Architecture and Urban Studies, Politecnico di Milano Via Bonardi 3, Milan, Italy \\ ${ }^{2}$ Department of Civil and Environmental Engineering, Politecnico di Milano Piazza Leonardo da Vinci, 32, Milano, Italy \\ ${ }^{3}$ Agencia Estatal Consejo Superior de Investigaciones Cientificas (MNCN, CSIC) Jose Gutierrez Abascal, 2, Madrid, Spain \\ ${ }^{4}$ Civil Protection Authority - Umbria Region, Via Romana Vecchia, Foligno, Italy \\ ${ }^{5}$ Direcció General de Protecció Civil, Barcelona, Spain
}

\begin{abstract}
Post event damage and needs assessment can supply fundamental information to feed risk models, i.e. data to define, calibrate and validate risk models. The lack or low quality of information regarding damage and losses collected in the aftermath of events conditions the quality of pre-event scenarios, thus affecting also the significance and the relevance of cost benefit analyses on mitigation measures to reduce the severity and magnitude of damage that are expected. Data collected in the aftermath of disasters are usually not suitable to this aim. Mostly, data on damage explicative variables (i.e. hazard, exposure, vulnerability and mitigation actions) are missing; damage data themselves can be also unsuitable as they refer to different spatial or temporal scales than those at which damage models work. In such a context, this paper presents results from the European Project IDEA (Improving Damage assessments to Enhance cost-benefit Analyses). The project is a response to the very limited reliability of data currently used to support cost-benefit analyses for natural hazards mitigation. The main objective of IDEA is an improvement of both damage data quality and procedures to collect and manage them. The paper focus in detail on the investigation of how improved damage data can better support the risk-modelling process. To this aim, the flood hitting the Umbria Region (Italy) in 2012 and the earthquake event that stuck the municipality of Lorca (Spain) in 2011 were investigated. Observed damages and damage predictions based on data that were available before the disaster have been compared. The comparison had several objectives:

- to verify the reliability of damage models that are currently used for damage estimation and that are proposed in literature;

- to identify data gaps in pre-event assessment that could be narrowed by better damage data. This is relevant for showing what data are currently missing in risk modelling but could be obtained at reasonable costs;

- to identify sectors for which pre-event damage assessment cannot be carried out or is carried out at the expense of large uncertainties and/or roughness;

- to show how improved risk modelling could better feed cost benefit analyses of pre-event mitigation measures.
\end{abstract}

Keywords: Flood damage models, cost-benefit analysis, flood risk mitigation, damage assessment

\section{Introduction}

The idea that good quality damage data are essential to risk prevention is not new (see for example the rather ample discussion provided by [1]). The main limits of existing collected data and databases are summarized in two recent reports by JRC ([2,3]). The lack of reliable, consistent and comparable damage data to understand damage mechanisms and to support the development of reliable damage models has been seen as an obstacle for reliable risk assessment, by several authors (see e.g. [4, 5]). Limitations of available flood damage data are mainly due, in this case, to the intent for which data have been collected in the past. Most of existing flood damage databases were created to support the loss accounting and compensation processes by private and public agencies. Coherently, information on damage explicative variables (i.e. hazard, exposure and vulnerability) was rarely collected, limiting the possibility of exploring damage mechanisms and of developing reliable damage models (see e.g. [6]). Another problem concerns the spatial scale of the assessment; most of existing flood databases supply only aggregated damages at the meso- or macroscale (i.e. at the level of a municipality, a province or a region) whereas information at the micro-local scale is also required for damage modelling, depending on the asset under consideration. At last, damage modelling requires sector based information (damage to buildings, roads, industrial activities, etc.), while most of times only the total damage is reported. As in the case of flood event, it is clearly very important to verify to what extent pre-event damage assessment correspond to at least in terms of gross quantities to the impact of real event. Even though risk assessment and scenario modelling is much

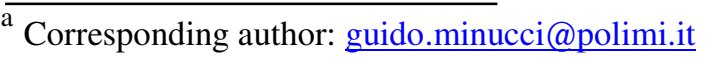


more advanced in seismic risk sectors, limits in the reliability of current damage estimations to industries and critical infrastructure can still be highlighted.

Within this context, the IDEA (Improving Damage assessments to Enhance cost-benefit Analysis) project aims at developing enhanced methods and tools for the collection, analysis and use for multiple purposes of disaster loss data (e.g. victims' compensation, forensic investigation to support sustainable recovery and reconstruction, improvement of current risk assessment models).

This paper shows the results of a comparison process between damage predictions based on data that were available before the disaster and observed damages respectively in the case of the Umbria flood in 2012 and the earthquake event in Lorca in 2011, with the main objective of understanding how improved damage data can better support the risk-modelling process.

\section{The Umbria Case Study}

\subsection{Background}

The Umbria region is located in the central Italy. Here, between the 12nd and the 14th of November 2012 diverse rivers have exceeded the alarm and flooding thresholds causing significant effects on the ground. The flood event with a return period of 200 years for the Paglia and Nestore rivers has occurred affecting 58 municipalities, and in particular the municipalities of Marsciano, the hamlet both of Ponticelli (Città della Pieve) and Orvieto Scalo (Orvieto), damaging directly and indirectly populations, infrastructures and buildings as well as industries, farms, and public services supply. Orvieto is located in the province of Terni, in the southwest area of Umbria. The city has a population of about of 21,500 and it is divided into downtown Orvieto and Orvieto Scalo. The flood did not affect Orvieto, while in the case of Orvieto Scalo water has reached its peak in a very short time and the height recorded in this area was between $1 \mathrm{~m}$ and $2.30 \mathrm{~m}$. This area acts as hub of connection linking Orvieto to Rome since here are all located the train station, bus station, and the highway. Moreover, here are located the majority of industrial activities.

\subsection{Flood-IMPAT in a nutshell}

Before this flood event, an analysis of past flood events in Umbria was carried out jointly with the Umbria Regional Civil Protection department. This research showed that data were not suitable as information concerning vulnerability of residential and economic vulnerability or damage to infrastructures were missing as well as data refer to different spatial scales than those at which the developed model, Flood-IMPAT FloodIMPAT methodology (i.e. Integrated Meso-scale Procedure to Assess Territorial flood risk) ([7]), works.

Coherently with the definition of risk (i.e. damage) as a combination of hazard, exposure and vulnerability
([8]), the Flood-IMPAT methodology requires the following steps: hazard assessment, vulnerability assessment, exposure assessment, and damage assessment according to the hazard and the vulnerability of exposed assets. The procedure has a modular structure, composed of independent modules. Each module refers to a specific exposed sector (e.g. residential buildings, infrastructures, and people) and a specific type of damage (i.e. direct, indirect, and intangible). While the procedure for hazard assessment is common to all modules, models for exposure/vulnerability and damage assessment are specific for each module, and independent from each other. This way, the procedure can be implemented or changed module by module, avoiding that a singular change would affect the entire procedure.

Within the IDEA project, the Flood-IMPAT methodology was implemented to reproduce impacts observed after the November 2012 flood event in Umbria. Furthermore, a comparison between the modelled damage estimations based on data that were available before the disaster and the observed data has been carried out.

\subsection{Pre-Damage Assessment}

The methodology has been applied focusing in particular on the municipalities of Città della Pieve and Orvieto (Figure 1). As hazards maps were used the maps elaborated by the Tiber River Authority. However, such maps and related reports do not provide water velocity and heights in case of flooding, therefore while running the model different heights were used to develop ex-ante scenarios of flooding. Here we will present the results for the height of $1.50 \mathrm{~m}$ and their comparison with real data collected on the field. With reference to the exposure, the Corine Land Cover is used distinguishing between different land uses and to each type of soil has been associated an economic value. Data used for the monetary value $(€ / \mathrm{mq})$ of residential buildings is taken from Real Estate and Property Price Database (OMI, in Italian, acronym of Osservatorio del Mercato Immobiliare), and the total floor surface area of buildings per census block is supplied by the national statistical office (ISTAT, in Italian, acronym of Istituto Nazionale di Statistica). With regard to industrial activities, reference was made to the classes of ATECO by ISTAT; also in this case with the awareness of the limits of a procedure that does not consider the size of the activity in terms of employees, but works only on the basis of the surface exposed.

\section{Damage assessment analysis}

In the case of the flooded area of the Municipality of Orvieto, a double assessment was carried out applying the Flood-IMPAT procedure: the first based on official data (PAI - hydrogeological plan, in Italian, acronym of Piani di Assetto Idrogeologico - in force at the time of the flood and the land use provided by the Corine Land Cover). The second evaluation was conducted by changing both PAI using the revised PAI and the Corine 
Land Cover land use layer, which was erroneously reporting the prevalent residential use, whereas in reality it is industrial. Obviously, setting the entire area as industrial contributes to make an error in the assessment at the local scale, but such error is much smaller than to consider this area as only residential. With reference to this, first assessment estimates damages for 1,799,389 € to residences and $0 €$ to industries, whereas the second analysis appraises industrial and residential damages respectively for $26,527,012 €$ and $0 €$ (Table 1 ). In parallel to damage estimation, a reconstruction on the real damage occurred has been carried out on the basis of a table with the total amount of damages claimed by companies set up by the Municipality of Orvieto integrated with the data of the individual tabs collected by municipal police in response to complaints of the companies affected. As results from the analysis of the real data, the total industrial damage results to be of $27,268,872.85 €$. Therefore, by comparison between the estimation data with the real data there are no damages to the productive activities in Figure 1a, which uses the land uses of the database Corine Land Cover 2006, while damage are evident in the map at the bottom in Figure 1b, in which the residential use has been converted to industrial use. Consistently with the previous results, the analyses concerning industrial activities focusing on damages to structures and to contents show the discrepancy in the results according to the land use applied while running the model. Hence, it must be said that in order to realize a good damage assessment a good information as input is essential to reach consistent and reliable results. Yet, once lowered the error due to the erroneous land use in the Corine Land Cover data, the Flood-IMPAT procedure shows on the base of the obtained results a good level of reliability.

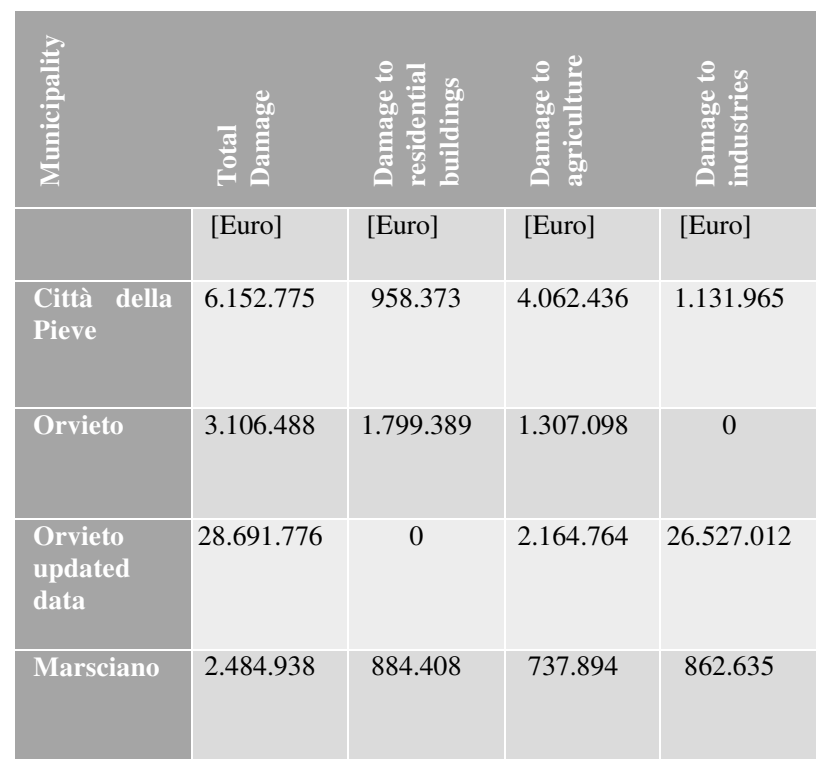

Table 1. Expected damages according to the Flood-IMPAT procedure
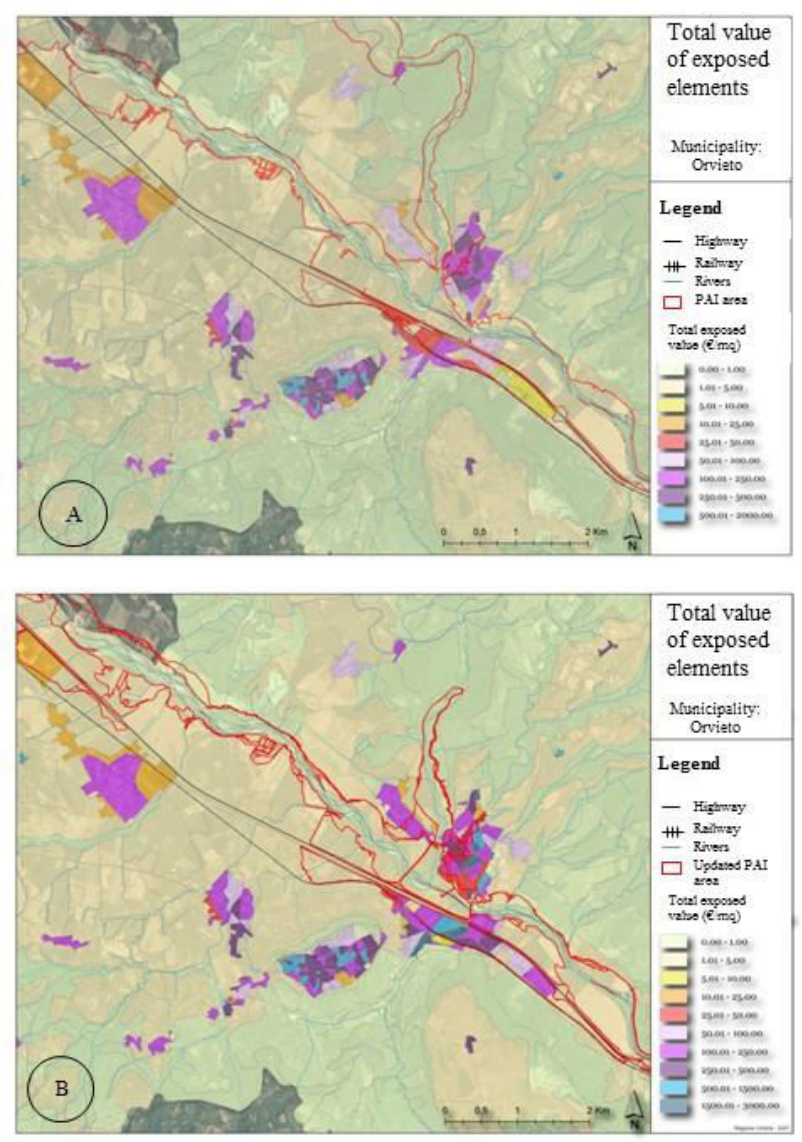

Figure 1.Expected damages to industries on the basis of the official PAI (a) and on the basis of the revised PAI (b.)

Further analyses have been carried out with reference to agriculture damages and population at risk. Regarding the latter (population at risk), the assessment map shows mostly a low level of risk due probably to the low level of population attributed to the statistical unit. In details, in the Southern area of Orvieto Scalo, nearby the Adunata Bridge, there is a parking plot identified as a gathering point in the municipal Civil Protection plan, which was completely flooded in 2012. As it can be notice such area is not pointed out by the damage assessment underlining the need: (1) to collect more accurate data to better perform damage assessment analysis; (ii) to integrate damage assessment with mitigation strategies; (iii) to integrate modelling activities with local knowledge.

The damage assessment executed for the Municipality of Città della Pieve highlights that the residential and industrial areas located in the hamlet of Ponticelli in the municipality of Ponticelli have the highest economic value. However, it is worth noting that the industrial area of Città della Pieve was not fully mapped in the land use map, the Corine Land Cover 2006, available at the time of the flood event in 2012. Therefore, the lack of a more detailed land use map affected the pre-damage assessment resulting in an underestimation of the damage to industries. Besides, the analysis at the meso-scale carried out to assess the expected damages to residences in the hamlet of Ponticelli (Figure 2a) shows how all the residential area should be damaged according to the selected damage scenario. However, the comparison between the expected damages with the data collected on 
the field regarding observed damages to residential buildings (Figure 2b) shows that not all the buildings were affected by the flood event in 2012. It is worth noting thus that having data as those collected in the aftermath concerning vulnerability of the residential building placed in this area would be helpful to increase the accuracy in the pre-assessment evaluation.
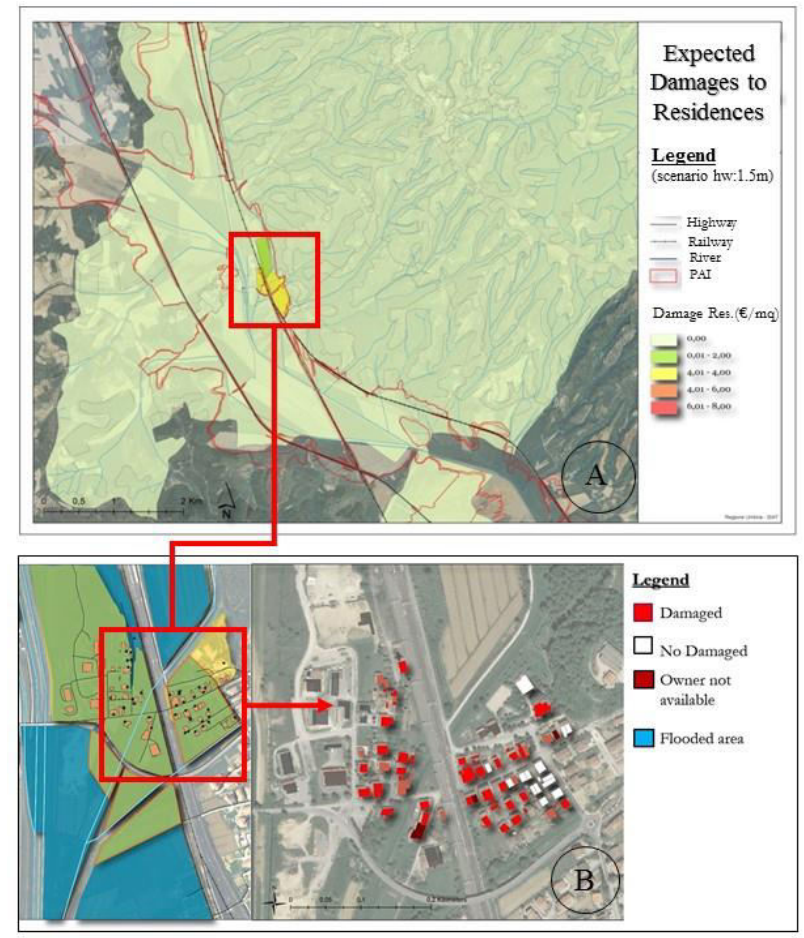

Figure 2. Expected damages to residential building (a) and observed damages (b) within the flooded area in the hamlet of Ponticelli (2012).

\section{The Lorca Case Study}

\subsection{Background}

A magnitude 5.2 earthquake shook the city of Lorca, in Murcia region (SE-Spain) on 11 May 2011 at 18:47 local time. The main shock was preceded by a large magnitude 4.5 foreshock, about two hours before. The strongest aftershock, around four hours later, reached magnitude 3.9. The event caused 9 fatalities and more than 300 people injured in a town with a population of around 60,000 in an area of $7 \mathrm{~km}^{2}$. More than 1,000 buildings, including residential, cultural heritage, schools, government buildings, healthcare, security facilities, etc., were severely damaged. Nearby towns and provinces were not seriously affected. Direct losses are estimated at $1,000 \mathrm{M} €$.

Damage was concentrated in several areas of the town where around $40 \%$ of buildings were affected. In the historical centre $16 \%$ of buildings were damaged. Historical heritage was severely affected including old churches and medieval wall towers (Figure 3). In some cases damage to historical buildings was aggravated by previous repair works undertaken which had used rigid reinforced concrete elements that had changed the nature of the original structures.

Earthquake damage data, in general, is very scarce in Spain. The level of seismicity is moderate, and useful information on earthquake damage is usually not available. Most recent significant damaging events in SE Spain occurred in the XIXth and XXth centuries (1956, 1884 and 1829). Since 1674 (intensity VIII) Lorca did not experience significant earthquake damage; thus the data from the 2011 event provides the only reliable information on earthquake damage covering the actual different typologies of construction (i.e., historic and traditional masonry, reinforce concrete) useful for risk and damage modelling.

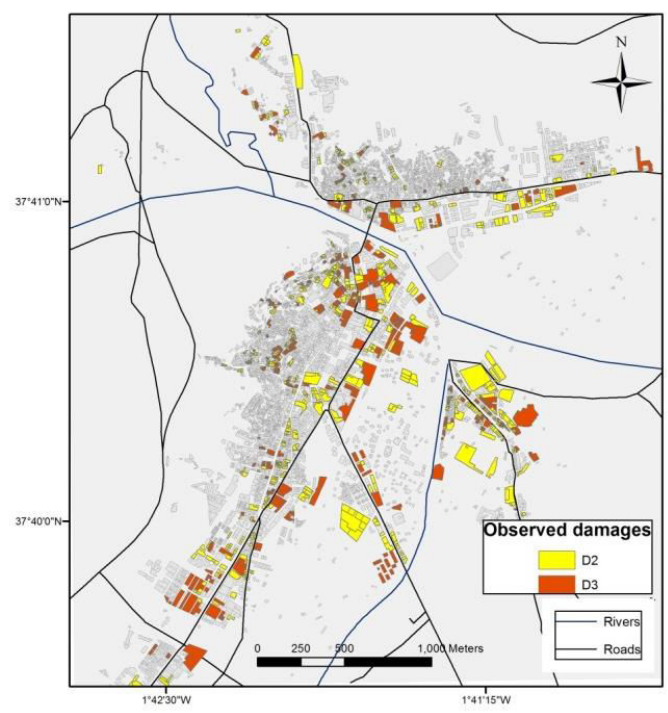

Figure 3. Observed building damage in terms of mean damage grade (only grades 2 and 3 after a scale of five from no damage, D0, to collapse, D4/D5) for the 11 May, 2011, Mw 5.2 Lorca earthquake (source: DG Citizen Security and Emergencies of the Region of Murcia).

\subsection{Risk and damage modelling. Earthquake scenarios}

Among other approaches, pre-event earthquake damage can be modelled by damage scenarios corresponding to a specific earthquake event. In this case, the simulation approach can be calibrated from known effects of past earthquakes. Several approaches for risk modelling have been developed in the last years, both, by public agencies and research institutions, e.g., HAZUS ([9]), EQRM ([10]), and by private companies, mainly insurance related, e.g., CAT ([11]), CRESTA (https://www.cresta.org/); and more recently, the OpenQuake project by the GEM Foundation ([12]).

Other than ground motion hazard, two basic ingredients are required for the estimation of expected damage at urban scale: relevant information about the building stock, and a methodology to translate it in terms of physical vulnerability. Early vulnerability methods started in the seventies in Japan and USA, being 
developed in Europe during the eighties ([13]). Main European vulnerability methods include GNDT ([14]), Risk-UE ([15]), and VULNERALP ([16]). They mostly evaluate physical vulnerability in terms of a normalized vulnerability index, $\mathrm{V}$.

The Risk-UE approach, originally developed to become a European standard, was selected to perform simulations of physical damage to buildings in the city of Lorca. The Risk-UE vulnerability index is obtained by adding several factors that consider building typology, building behaviour modifiers (e.g., preservation, discontinuities/irregularities, or quality of construction), and a regional factor accounting for regional material and construction practices. For each building typology the vulnerability index is bounded by two extreme values (minimum and maximum). The physical damage, in terms of mean damage grade (mdg), is then estimated as a function of the seismic load, characterized by the macroseismic intensity, and the vulnerability index ([15]). This procedure (direct approach) allows also obtaining estimates of the building vulnerability index from the observed damage and the macroseismic intensity when applied backwards (indirect approach).

\subsection{Damage simulation. Direct approach}

Using the information on buildings in Lorca from the Spanish Cadastre (http://www.sedecatastro.gob.es/), a preliminary building typology classification was established considering the age of construction and the number of floors, obtaining up to six different building typologies. Then, the vulnerability index was obtained by applying the Risk-EU methodology.

The simulated physical damage to buildings (mdg), based on the relationship between intensity (estimated in Lorca as VII in the EMS98 scale), damage and vulnerability by ([15]), is depicted in Figure 4.

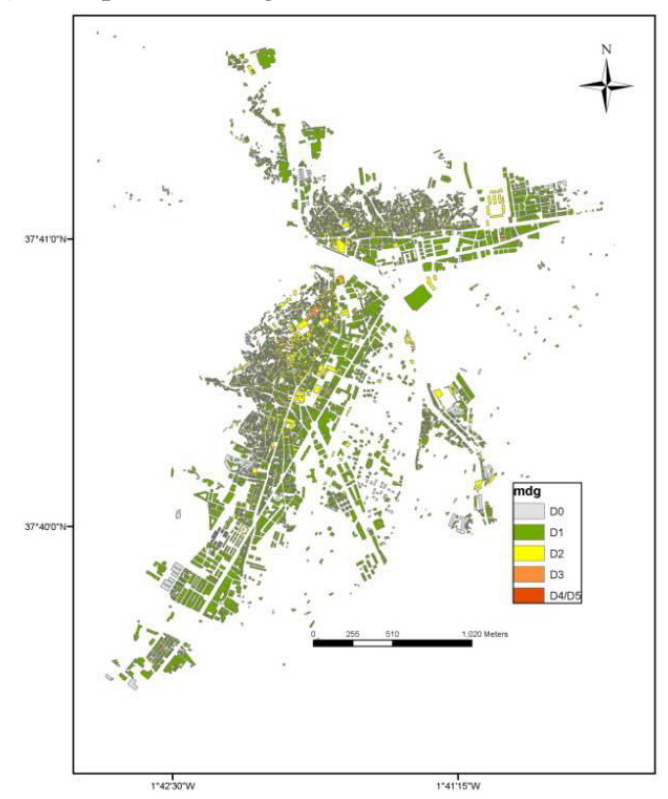

Figure 4. Simulation of physical damage to buildings in Lorca. Direct approach

When comparing with the observed damage (Figure 3), the results suggest a general underestimation of the vulnerability index. The additional vulnerability factors, such as state of preservation, orientation, discontinuities, soft-story, plan/vertical irregularities, openings, or quality of construction, were not considered at this stage. Possible previous effects, if any, of the magnitude 4.5 foreshock were also not considered.

\subsection{Damage simulation. Indirect approach}

Through combining the observed building damage in Lorca (Figure 3) with the estimated observed intensity (VII), estimates of the vulnerability index are obtained by applying the Risk-UE procedure backwards. Figure 5 shows the corresponding damage simulation, which is very close to the observations (Figure 3 ). The estimated vulnerability index values are larger than those estimated based on the direct approach. Still the values are within the expected range for the corresponding building typology ([15]). It is worth to point out that for some buildings this estimated value is very close to the expected upper limit.

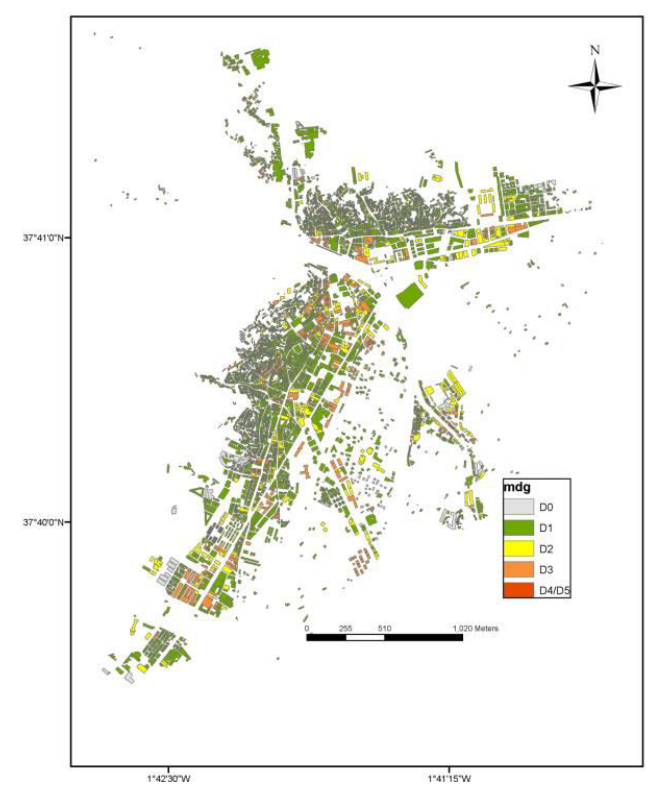

Figure 5. Simulation of physical damage to buildings in Lorca. Indirect approach.

\section{Discussion}

The analysis in section 3 highlights that absolute damage values can change significantly according to the implemented model. At the same time, accurate estimates are required to carry out cost-benefit analyses. Models validation is thus desirable in the future, the aim being to identify the most suitable model for investigated context; however, a problem arises in this regard about the current lack of data on past flood events. From another perspective but linked to earlier point, results uncertainty should be investigated. Although a deterministic approach is implemented in Flood-IMPAT, several sources of uncertainty can be identified which influence results reliability; among them it is the uncertainty about 
exposure values and damage models as shown by the Umbria case study. Confidence intervals should be then identified for damage assessment results so that decision makers are aware of their uncertainty when mitigation strategies are discussed. Again, comparison with past data is required. It is important to stress that not only damage models should be investigated but also models for exposure estimation. Indeed, this is a crucial aspect on which literature rarely focused in the past; existing models for exposure estimation should be verified and new models should be developed where they do not exist.

As shown by the case of Città della Pieve, the lack of a more detailed land use map as well as of a residential building characterization did not allow: (i) to feed the model to obtain a more accurate assessment at the local scale of (future) damages and; (ii) to better understand the causes for which some buildings placed within the flooded area were not damaged. Hence, the case study underlines two main issues. On one hand, the fact that risk-modelling outputs may be conditioned by the quality of data input. According to this, it is worth to note that, as a general norm, the selection of mitigation strategies should not be based only on meso-scale analyses but more specific studies are required, e.g. micro-scale/object oriented analysis taking into consideration also those facets that cannot be assessed by methods working at the meso-scale. On the other hand, it raises the need of a better understating of how information on land use coverage (i.e. vulnerability) influences damage assessment in terms of the spatial distribution of damage. Linked to these two points, a further factor refers to the need to collect flood damage data in the aftermath in a manner useful to create consistent and reliable flood databases, which meet the objectives of risk mitigation, before and after floods occurrence.

The Lorca case study represents a different approach to the analysis of damage assessment. First, it corresponds to a sudden onset event, which implies different hazard approaches; and second, the selected methodology for physical vulnerability and damage assessment, Risk-EU, is derived from the modelling and definitions provided by the European macroseismic scale EMS98, which uses mainly a qualitative appraisal for assigning values to relevant parameters. The uncertainty involved in the procedure is handled making use of probability and fuzzy-set theories, which provides 'probable' and 'less probable' vulnerability index and damage ranges ([15]). The comparison of both, the direct and indirect approaches for damage simulation, evidences that additional modification factors of the vulnerability, like those identified earlier, should be considered when developing risk scenarios. Calibration of the models is key provided that damage data is available, which is not always the case in moderate seismic activity regions. Simulation approaches and subsequent calibration provide a very useful tool for improving pre-event modelling in the establishment of prevention and mitigation measures.

\section{Conclusion}

This paper describes the results of comparative analyses carried out between pre-damage assessments based on data that were available before the disaster and observed damages respectively in the case of the Umbria flood in 2012 and the earthquake event in Lorca in 2011. The study highlights the main limits related to the real implementation of available models both in case of flood and earthquake events; among them, the two most critical ones are usually the lack of or the low quality of data (i.e. exposure data, damage data) for feeding risk models or against which models can be validated.

According to this, the research activity carried out shows how damage data that now are not collected or are not collected in reliable and consistent manner could not only be obtained at a reasonable but they would improve pre-assessment analysis. Moreover, the paper shows how handling uncertainty may improve risk-modelling capacities opening the floor to several innovations whereas models/tools for damage estimation are lacking.

\section{References}

1. Dauphine A. (2000). Risques et catastrophes. Observer - Spatialiser - Comprendre - Gérer, Armand Colin, Collection U. 799.809.

2. De Groeve T., Poljansek, K., Ehrlich D. (2013) Recording Disasters Losses: Recommendation for a European Approach. JRC Scientific and Policy Report [online]. Available at: http://publications.jrc.ec.europa.eu/repository/bitstrea m/111111111/29296/1/lbna26111enn.pdf

3. De Groeve T., Poljansek K., Ehrlich D., Corbane C. (2014). Current status and best practices for disaster loss data recording in EU Member States. JRC Scientific and Policy Report [online]. Available at: http://publications.jrc.ec.europa.eu/repository/bitstrea m/JRC92290/lbna26879enn.pdf

4. Merz B., Kreibich H., Thieken A., Schwarze R. (2010). Assessment of economic flood damage. Nat Hazards Earth Syst Sci., 10, 1697-1724.

5. Meyer V., Becker N., Markantonis V., Schwarze R., van den Bergh J.C.J.M., Bouwer L.M., Bubeck P., Ciavola P., Genovese E., Green C., Hallegatte S., Kreibich H., Lequeux Q., Logar I., Papyrakis E., Pfurtscheller C., Poussin J., Przyluski V., Thieken A.H. and Viavattene, C. (2013). Review article: Assessing the costs of natural hazards - state of the art and knowledge gaps. Nat. Hazards Earth Syst. Sci., 13, 1351-1373.

6. Molinari D., Ballio F., Handmer J., Menoni S. (2014). On the modeling of significance for flood damage assessment, International Journal of Disaster Risk Reduction, 10, part A, 381-391.

7. Molinari, D., Ballio, F., Menoni, S. \& Legnani, L. (2013). Implementing the Floods Directive: a procedure for flood risk analysis and mapping, Proceedings of 35th IAHR World Congress, 8-13 September 2013, Chengdu, China 
8. UNDRO - Office of the United Nations Disaster Relief Coordinator (1979). Natural disasters and vulnerability analysis. Office of the United Nations Disaster Relief Coordinator (UNDRO), Geneva.

9. FEMA (2010). HAZUS-MH MR5 Technical Manual - Earthquake Model, U.S. Department of Homeland Security, 736 pp.

10. Robinson D., Fulford G. and Dhu T. (2006). EQRM: Geoscience Australia's Earthquake Risk Model: Technical Manual: Version 3.0.1 ed. Record 2005/001. Geoscience Australia, Canberra.

11. Grossi P. and Kunreuther H. (eds.) (2005) Catastrophe Modeling: a New Approach to Managing Risk, Springer, 245 pp.

12. Silva V., Crowley H., Pagani M., Monelli D and Pinho R. (2014). Development of the OpenQuake engine, the Global Earthquake Model's open-source software for seismic risk assessment. Natural Hazards, 72:3, 1409-1427.

13. Senouci A., Bard P-Y., Naboussi Farsi M., Beck E., Cartier S. (2013). Robustness and uncertainties of seismic damage estimates at urban scale: a methodological comparison on the example of the city of Oran (Algeria), Bull Earthquake Eng., 11, 1191-1215.

14. Benedetti D., Benzoni G., Parisi M.A. (1988). Seismic vulnerability and risk evaluation for old urban nuclei, Earthq Eng Struct Dyn, 16(2), 183201.

15. Lagomarsino S., and Giovinazzi S. (2006). Macroseismic and mechanical models for the vulnerability and damage assessment of current buildings. Bull. Earthquake Eng., 4, 415-443.

16. Guéguen P., Michel C., LeCorre L. (2007). A simplified approach for vulnerability assessment in moderate-to-low seismic hazard regions: application to Grenoble (France), Bull. Earthquake Eng., 5(3), 467-490. 